explores the concept of disease and concludes that the word means different things to different people at different times. To illustrate the changes in medical thought, we begin an historical tour in ancient Egypt where we find that the first recorded doctor, Imhotep, fulfilled twin roles as priest and physician. After perilously few words we find that the medical profession has adopted a modern, empirical philosophy and a sciencebased practice.

Having dealt with 30 centuries of medical history we now consider the history of philosophy and how it affects medicine. We are introduced to the strengths and weaknesses of inductive logic as proposed by John Locke and John Stuart Mill and then to the weaknesses of deductive reasoning as proposed by the ancients such as Aristotle, and in more modern times by Leibniz. The conclusion is that both inductive and deductive logic are defective as a basis for scientific discovery. What is preferred is a Popperian hypotheticodeductive model: here the hypothesis, and not the slavish collection of facts, is the goal of the scientifically minded doctor. Starting with the hypothesis, deductive logic allows the formulation of predictions which, if the theory is a good one, must be amenable to falsification by scientific means.

Bradley now points out that, for all our ingenious hypotheses and well constructed experiments, there is a limit to knowledge. Heisenberg showed that there is a fundamental limit to the amount we can know about the world, similarly, Gödel's incompleteness theorem proved that whatever the basis of a formal system, there are false propositions which cannot be proved to be false. These theoretical limits to our knowledge of the world, and the models we construct, are well known but they have not discouraged biological and medical investigation. Of greater significance is the concept of the organism as a non-linear, chaotic system. It is a pity that more is not said about the implications of chaos theory for our understanding of disease and epidemiology.

Bradley suggests in chapter three that there is a hypocrisy in the teaching of medical students. The teacher advocates 'think how I say I think, not how I actually think'. A distinction is drawn between the intuitive practice of the consultant, and the painstaking analytical approach of the houseman on his first day.

Bradley goes on to describe how the analytical doctor can best use clinical investigations to help in diagnosis. Bayesian notation is introduced as a convenient way of calculating the probability of a disease, provided that the sensitivity and false-positive rate of the test is known. To complete the calculation, the doctor must estimate the prevalence of the disease in her given population; it is clear that these estimated probabilities must vary radically between a GP's surgery and a specialist clinic. Despite this subjective element at the heart of the system, Bradley states that 'even imperfect data is infinitely preferable to no data'. This is a bold statement, especially when considering the work which shows that a physician's accuracy at assessing prior probability is very poor.

Chapter five takes formal probability estimation one step further and asks whether computers can diagnose disease. The section entitled 'Can computers think?' gives short shrift to proponents of artificial intelligence and favours the sceptics such as Searle and the Dreyfus brothers. Nevertheless, Bradley finds the prospect of 'computer assisted' diagnosis exciting; De Dombal's acute abdomen system is of special interest, not least because it has significantly increased diagnostic accuracy in his unit.

Having made a diagnosis the next question is how rationally to proceed with management. A brief discussion of QALYs, utility and life-expectancy analyses suggests that formalised decision-making need not be dehumanising but may, in certain instances, empower the patient to control the course of her treatment. Considering the philosophical content of other sections of the book, the ethical implications of decision analysis deserved more attention.

In summary, this book is about doubt but not about confusion. If Bradley's protégés need a motto it could well be 'Doctor sum, ergo dubito'.

DAMIAN C CROWTHER Medical Student, Oxford

\section{The ethical dimensions of the biological sciences}

Edited by R E Bulger, E Heitman and S J Reiser, Cambridge, Cambridge University Press, 1993, 294 pages, $£ 35.00 \mathrm{hb}, \$ 54.95$, $£ 12.95 \mathrm{pb}, \$ 18.95$
Experimental science is hard work, time-consuming and absorbing. It is characteristic that scientists consider the ethical aspects of their work only during coffee-time, until a problem arises concerning, say, authorship or scientific fraud. But the essence of ethics in science is to anticipate the problems, to lay down a suitable framework for the ethical treatment of people in science and of scientific problems. This book is not an attempt to make a coherent moral philosophy of the biological sciences, but rather an anthology of thirty-five short chapters, each by a different author, on aspects of ethics in biology. The aim of many of these chapters is to make explicit codes of practice that have long been implicit in good science. These range from the 1949 Nuremberg Code (chapter 16), via canons of gentlemanly behaviour, to recommendations for good housekeeping of data in the lab. There are also sections on research using animals, research on humans, human genome research, fraud and selfdeception in science, and conflict of interest in collaboration between scientists and industry.

In his introduction, Reiser distinguishes four phases in the growth of importance of ethics in biological research and medicine since World War II. The last of these is the acceptance that 'training' in ethical issues should no longer go by default, but must be made explicit, because of the greater power of science, the greater public awareness of the good and bad in science, and the new ethical problems raised by new discoveries. The growing interest in ethics in the biological sciences is reflected in the dates when these chapters were first published: of the 35 chapters, 25 were published in the last ten years.

Not all of the chapters directly concern ethics. The first section of the book contains two fascinating pieces, one by Arieti on creativity in science, and one by Comroe and Dripps on the analysis of publications in cardiology. Although these pieces are interesting, their relation to the ethical issues in the rest of the book is not obvious. Glass (chapter 3) has one of the few chapters that considers the broad ethical basis of science. $\mathrm{He}$ follows Bronowski in arguing from the premise that aspects of science are inescapably subjective because science is done by humans, to the axiom that "We ought to act in such a way that what is true can be verified to be so'. He does not stray into 
epistemology, even so far as to mention Popperian refutability, but the chapter is well written, and forms a useful basis for the rest of the book.

The problems of subjectivity in science are extended in chapters four to nine, in discussions of fraud, gullibility and the resistance of scientists to scientific discovery. These are now favourite subjects in the public discussion of science, and some of the thorny issues that result in tension between scientists and science writers are well explored by Nelkin in chapter 33, 'The high cost of hype'.

Many of the authors writing in this book deny that there are, or should be, rules that govern the behaviour of scientists, but consider that there should be suggestions for the guidance of workers. In a short chapter on this subject (chapter 23), the Harvard University Faculty of Medicine has summarized the guidelines that it provides for its own research workers. This is an excellent, succinct summary, which has obviously been written by practising scientists, and which leaves ample room for manoeuvre by the very different characters that turn up in scientific research. The following chapter, which is an equivalent set of guidelines from the National Institutes of Health, is more prolix and polysyllabic, and contains more grand generalizations than simple practical guidance. Chapter ten reproduces a report from the National Academy of Sciences in the USA, 'Responsible Science: Ensuring the Integrity of the Research Process'. This, like the Harvard Medical School guidelines, is clearly written, succinct and pragmatic, and again has the air of being written by people who actually do science and who are trying to improve it. They divide unacceptable behaviour in science into three categories: 1 . scientific misconduct; 2 . questionable research practices, which do not directly damage the fabric of science but which weaken it in various ways, for example, the use of inappropriate statistical tests that enhance the significance of data, and 3. misconduct, such as harassment of colleagues, that is not related to research.

The panel that wrote this report warns that it is risky to design policies to deal with all possible instances of inappropriate behaviour, because the circumstances differ so widely between cases.
Caplan provides a highly readable account (chapter 21) of issues underlying the ethics of animal experiments, in which he refutes Singer's utilitarian view of animal sentience, and argues that purposiveness is a better criterion than sentience for assessing the moral worth of an entity. He then argues rather briefly against moral absolutes, observing that human interests are bound to conflict with those of other organisms. I would like to have seen a more explicit discussion of how, both philosophically and politically, 'rights' are assigned to entities as a result of their sentient and purposive powers. Surely rights are assigned by humans: they are not inherent and do not have absolute and independent existence.

Huth has a useful piece on bad publishing practice in scientific research (chapter 14), in which he condemns the division of results into least publishable units (LPUs), otherwise known as salami science. Perhaps a few statements like those made by Huth should accompany the instructions to authors in all scientific journals. Lomasky (chapter 29) exposes the speciousness of the argument that an academic should be motivated only by the search for knowledge, while others can pursue their work for profit. As he points out, if a barber cuts hair for profit, why should a scientist not gain knowledge for profit? There need be nothing immoral about this; indeed, provided that results are openly shared, the knowledge gained from science rapidly becomes a public resource - unlike hair.

Considering that it must have been written by a committee, chapter 30 , 'Patenting life', provides a surprisingly readable summary of the most important questions raised by the patenting of artificially altered organisms, such as bacteria, transgenic mice, etc. Murray (chapter 35) introduces some of the ethical questions in human genome research but, considering the rapidly growing importance of this problem, particularly in the public mind, it would perhaps have been appropriate to include more chapters on this subject.

Each section of the book ends with some questions for discussion and references for further reading. As the book is presented, I only found one irritating omission: there are no details about the authors - where they work and what they do. This would have been very interesting, since they range from philosophers to laboratory workers.

Because of the breadth of the ethical questions considered in this book, it will obviously be an extremely useful source book on courses in scientific ethics, particularly in the biological sciences. For the same reason, and because each chapter is quite short, the book also makes a highly useful source for busy scientists to dip into a good source for coffee-time moral philosophers.

DR CHARLES R M BANGHAM है Consultant Virologist, Islip, Oxfordshire

\section{The harm we do: a Catholic doctor confronts Church, moral and medical teaching}

Joyce Poole, Mystic, Connecticut, Twenty-Third Publications, 1993, 168 pages, $\$ 12.95$

Dr Poole is a Roman Catholic who has or spent a working life in medical practice in the National Health Service (NHS), much of it as a general practitioner. Her book is an account of the conflicts and difficulties faced by a doctor with a

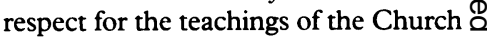
when striving to find a humane and $\overrightarrow{\vec{B}}$ helpful response to a patient in distress, either physical or mental. Throughout, $\underset{\mathcal{T}}{\vec{T}}$ she illustrates her discussion with case $\frac{7}{0}$ histories from her own experience, and these strongly reinforce her main argument, which is that dogmatic general principles always need to be applied sensitively in response to individual need.

In making the point that in some instances the most genuinely com-음 passionate help a doctor can offer is $D$ an abortion or sterilization - both for-음 bidden by the official teaching of the Roman Catholic Church - she is noto embracing a purely situational, rela- $N$ tivist ethic. Her book can be read as 스 reflections on the problems faced by $\omega$ a doctor and her patients living within a credal moral framework thate in principle excludes certain courses $\mathbb{\Phi}$ of action from the outset. The con-? frontation of the title is chiefly with $\square$ the current attitude of the Roman $\bar{P}$ magisterium to sexual matters, especially its obsession with contra- $-\vec{D}$ ception. Most of her case histories are about sexual and reproductive problems - contraception (including sterilization), abortion, infertility ando HIV infection. She leaves the reader in no doubt that she regards the 